
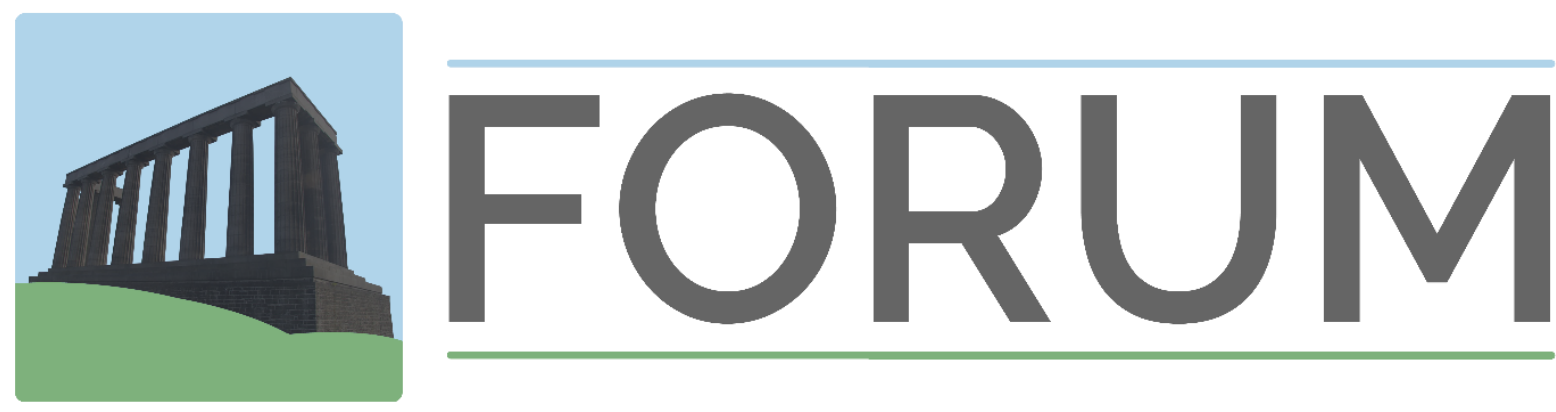

University of Edinburgh

Postgraduate Journal of Culture and the Arts

Issue 32 | Autumn 2021

Title

Bodies, Temporality, and Spatiality in Chen Chieh-Jen's Lingchi: Echoes of a Historical Photograph (2002) and Factory (2003)

Author

Hsin-Yun Cheng

Publication

FORUM: University of Edinburgh Postgraduate Journal of Culture \& the Arts

Issue Number 32

Issue Date

Autumn 2021

Publication Date

$01^{\text {st }}$ October 2021

Editor

Nicola Robertson

FORUM claims non-exclusive rights to reproduce this article electronically (in full or in part) and to publish this work in any such media current or later developed. The author retains all rights, including the right to be identified as the author wherever and whenever this article is published, and the right to use all or part of the article and abstracts, with or without revision or modification in compilations or other publications. Any latter publication shall recognise FORUM as the original publisher. 


\section{Bodies, Temporality, and Spatiality in Chen Chieh-Jen's Lingchi: Echoes of a Historical Photograph (2002) and Factory (2003)}

\section{Hsin-Yun Cheng \\ University of Rochester}

This article discusses Taiwanese artist Chen Chieh-Jen's (1960-) two early videos Lingchi: Echoes of a Historical Photograph (2002) and Factory (2003). By revisiting a historical photograph taken by a French soldier in 1905 and articulated by French philosopher George Bataille in 1961, Chen reworks the internal genealogy of imperialist violence from latenineteenth-century China to 1990s Taiwan in Lingchi. Lingchi reenacts a victim in the process of execution (death by a thousand cuts) from an old photo, which interrogates the violence of photography on a dying person and Bataille's fetishisation of the cultural Other. In one scene, the camera enters the subject's bodily orifices and shows two scenes: the sites of imperialist invasions in the early twentieth century as well as two laid-off women workers in 1990s Taiwan. Factory reorganises this group of laid-off women workers to work in the abandoned garment factory as if they stage a silent labour strike. This reenactment not only plays a prolonged and endless labour conundrum but also reveals the unequal economic relationship between Taiwan and the United States in Cold-War Taiwan, a continuation of imperialist domination in the postwar period. This article explores two dimensions: First, the aestheticisation of the suffering subject in Lingchi and how it debunks the Western gaze. Second, their communal subjects (the women workers) and the scenes in Lingchi and Factory reflect the continuation of imperialist domination in Taiwan under globalisation.

\section{Introduction}

Taiwanese artist Chen Chieh-Jen's works have long been devoted to issues of postcoloniality, labour, and social justice in post-Cold-War East Asia. Reflecting on the influences of imperialism and the expansion of capitalism in East Asia, his well-known video Lingchi: Echoes of a Historical Photograph (2002), a three-channel, 21 minutes and 4 seconds video installation, reenacts an infamous historical photo depicting the execution of an ancient Chinese punishment lingchi (colloquially known as death by a thousand cuts). Related to this 
film, Chen's Factory (2003), a single-channel, 31 minutes and 9 seconds video installation, was made in the year after, focusing on the repercussions of capitalist exploitation and the wave of unemployment in 1990s Taiwan. These two works specifically present alternative ways to reconsider the history of colonial subjects. In addition, Chen calls our attention to the imperialist violence and possibilities of reinterpretation in different media — photography and video. By analysing Lingchi and Factory, this article examines Chen's aesthetic approach of representing the image of suffering subjects in postcolonial East Asia.

Among the English literature discussing Chen's works, Chu-Chiun Wei provides a comprehensive and critical lens to examine the artist's intention from the perspective of political and social movements. Wei argues that Chen's works propose an approach towards the multitude in the postcolonial and neo-liberalist societies, indicating that these issues move beyond the national boundaries (68). Her argument circumvents a trap of a single and fixed identity in consideration of Taiwan's historical complexity. However, she discusses less about the interrelationship between Lingchi and Factory as well as the issues of postcolonial trauma and violence. Based on her argument, this article will touch more upon these aspects and the aesthetic dimensions.

Chen grew up in the martial-law period in Taiwan (1949-87). Many of his artistic works concern the repressed individual voices and the agency of the deprived people under a dictatorial regime. During this period, cultural production and fine art were inhibited through rigorous censorship. Under the pressure of the termination of American aid in the 1960s, the Kuomintang government (hereafter, KMT) opened export processing zones to galvanise economic growth. Although this policy successfully drew multinational companies to establish factories, the labour-demanding and contaminated plants had turned Taiwan into the world's factory. From then on, Taiwan has been incorporated into the division of the global capitalist system. However, since the late 1980s, manufacturing has moved overseas for cheaper labour; many workers were laid off overnight without severance or retirement pay. During the late martial law period, Chen and his friends organised a series of underground exhibitions entitled "Living Clay" (1986-1999), challenging the official artistic institution by showing and performing artworks at alternative spaces. After martial law was lifted in 1987, he suspended his art career for eight years, rethinking the complexity of democracy, politics, and capitalist structure in post-martial-law Taiwan. 
Lingchi was first screened at the 2002 Taipei Biennial on three screens, and later exhibited at many international events. Chen restages and fictionalises lingchi based on a historical photo, by turning it into a tableau vivant (or living picture). The original set of lingchi photographs addressed by Bataille in Les Larmes d'Éros (first published in 1961; English translation: The Tears of Eros) were reputedly taken by an unknown French soldier or photographer around 1905 and published in part in both George Dumas' Nouveau traité de psychologie (1939) and Louis Carpeaux's Pékin qui s'en va (1913). According to French historian Jérôme Bourgon, the photo that Chen appropriated in his video was mistaken by Bataille as an execution of a Mongol guard who killed his master. The criminal in this photo was, in fact, an anonymous young man who killed his mother and was sentenced to one of the most extreme penalties in the Chinese judicial system. (Bourgon, "Execution by lingchi of pseudo-Fu-zhu-li" and "Agony by proxy. Voices, views, and values about lingchi execution.") These kinds of photographs, often categorised as "supplices chinois" (or "Chinese torture," a photographic genre), were printed on postcards, commodifying exotic and brutal themes. Bataille received these postcards from his friend Dr Borel, one of the earliest French psychoanalysts (Berry 33).

\section{Genealogy of the Self and the Oriental Gaze}

Before analyzing Lingchi, it is necessary to introduce Chen's earlier photo series, Revolt in the Soul and Body 1900-1999 (1996-1999), because the first picture of this series, Genealogy of the Self (1996), is the prototype serving the Lingchi video. This series, consisting of nine digitally manipulated images, is the prelude to Lingchi and an exploration of the relationship between selfhood and modern violence in political regimes and imperialist invasion in historical events. This photo series can be divided into two parts: five pictures were manipulated from historical photos; four others were produced from the artist's imagination. The themes of the first five pictures range from the lingchi penalty (1905), castration as punishment (1904-1910), KMT's purge of communists in Northeast China (1927), the Musha Incident (Japanese massacre of indigenous people in Taiwan, 1930), and the communist massacre of pro-KMT villagers in the civil war (1946). These photos constellate violent scenes across the Taiwan Strait from the late Qing to the civil war period. Chen collected these historical photos from photo books such as History of Photography in China and Reawakening from Old Dreams: The Postcard Collection of Qing Dynasty (Liu, "The Gaze of Revolt: Chen 
Chieh-Jen's Historical Images and His Aesthetics of Horror"). Reprinting these low-fi photographs, Chen uses graphic software to repaint and manipulate the physiognomies of attendees or to add his nudes in the images.

Invoking Julia Kristeva's notion of “abjection”, Joyce C.H. Liu sees the violent scenes in Chen's Revolt as a way to "sublimate" mixed affects generated from the violence ingrained in his mother nation. In her theory of abjection, Kristeva argues that the obscene parts of the body are things that one wants to repel away from an individual or cultural body because of the unbearable feelings when encountering them. (Liu, "The Gaze of Revolt"). The punishment and brutal scenes - not only massacres but also incalculable arrests and executions under the martial law regime - for Chen, were officially hidden but authentically existed under the KMT regime. Liu observes that although a large part of the trauma and memory was wiped out by the KMT government, Chen still tried to recuperate the hidden images and trauma by flipping through the documents and remodelling them as his childhood memory, or the collective memory in the postcolonial and martial law period.

In Genealogy of the Self, Chen manipulated the victim's head into the depiction of a two-headed subject. He claims this metamorphosis resonates with multiple identities that exist in individual subjectivity. According to Chen, this imagery also echoes incarnation beliefs from three religious traditions: Daoist beliefs that a human has three immortal souls (Hun) and seven mortal forms of mood $(\mathrm{Po})$; the two-headed Buddha in the West Xia regime; and the god Janus in Roman mythology (Amy Huei-Hwa Cheng, "A History of the Photographed Subject: On Lingchi- Echoes of a Historical Photograph"). The multiple identities, or "schizophrenia" as he states, embody the split self in the postcolonial and globalised contexts. People of postcolonial countries are always the subjects who have "been looked at" or "been narrated" (Cheng, "A History of the Photographed Subject"). To reopen spaces for interpretation and to dissolve Bataille's dominant claim, Chen chooses to revisit traumas deeply rooted in the imperialist aggressions in modern China as well as capitalist exploitations in present-day Taiwan. Chu-Chiun Wei provides an instructive reading on the rebellion of the photographed subject in Lingchi. She argues that reenacting the static lingchi photograph is to "reclaim the agency for the photographic subject." (66) More importantly, by resisting the original context of how this photo was consumed in the West and making the lingchi victim performing in front of the camera, Chen situates the audience of Lingchi into undefined positions-e.g. the subject to be looked at, a part of the onlookers, or the accomplice of the executioners - and therefore, complicates the identity of the colonised Other. (73) 
In Bataille's interpretation, this particular image of suffering plays a dual role. On the one hand, he was shocked and anguished by the intolerance brought about by the punishment; on the other hand, he could not withhold the ecstatic and erotic subjective states the image evokes in him. As he expresses:

This photograph had a decisive role in my life. I have never stopped being obsessed by this image of pain, at once ecstatic (?) and intolerable... Through this violence-even today I cannot imagine a more insane, more shocking form-I was so stunned that I reached the point of ecstasy. My purpose is to illustrate a fundamental connection between religious ecstasy and eroticism - and in particular sadism. From the most unspeakable to the most elevated (Bataille 206).

Establishing his argument based on Christian religious tradition, Bataille transforms the sight of others' pain into divine ecstasy. His transfiguration and sublimation of religious martyrdom were later recuperated by Susan Sontag in her Regarding the Pain of Others (2003). Sontag holds that this image is intolerable in that it is the picture of a real figure instead of a mythical martyr taken by the camera. This "real Marsyas" obliges its viewers to confront extreme "atrocity." Bataille and Sontag not only view the lingchi excruciation as the "pain of others" but also base their interpretation on religious thinking, "which links pain to sacrifice, sacrifice to exaltation" (Sontag 98-99). Historian Jérôme Bourgon, and his partners Timothy Brook and Gregory Blue, criticise Bataille's interpretation. They point out that Bataille only takes the "face value" of photography, catering to his notion of "ecstatic suffering", but neglects the moral and cultural contexts in photography (Brook, Bourgon, and Blue 236-238). Their reconstruction of lingchi based on factual evidence sheds light on the discrepancy between Westerners' views and the perceptions held by peoples culturally linked to lingchi.

\section{Performing a Still Picture: Spectacles and Eroticised Subjects in Lingchi and Factory}

Lingchi is a black-and-white, mostly silent, thirty-two-minute video, which could be roughly divided into three sections. The first section is the early process of lingchi. This section focuses on the preparation of the punishment and the gaze of the on-site spectators. The executioners slowly strip off the victim's clothes and feed him liquid opium (Fig. 1). During the slicing process, the lens never captures the bloody flaying scene, which remains a suspended expectation to the viewers. The camera focuses on the victim's intoxicated 
expression as well as the stunned onlooker's faces. The deadpan countenance of the watching multitude starkly contrasts with the trancelike status of the victim. It is this uncanny moment that calls our attention to the agency of the photographed victim and spectators in the original lingchi photo. Although the victim was the one who suffered from the punishment, the onlookers in the video seem to be passive. The numbness of the onlookers is not only fictionalised and amplified in the video but also reminds us of a scene in modern Chinese writer Lu Xun's (1881-1936) short novel Scream (1922). In the prelude to Scream, Lu describes that he once saw a slide depicting a Chinese spy who was about to be decapitated by Japanese soldiers. The Chinese onlookers in the photo were indifferent and even came to "appreciate" (Jianshang) the cruel scene. Lu was disappointed by the "uncivilised" masses in modern China (Berry 28-32).

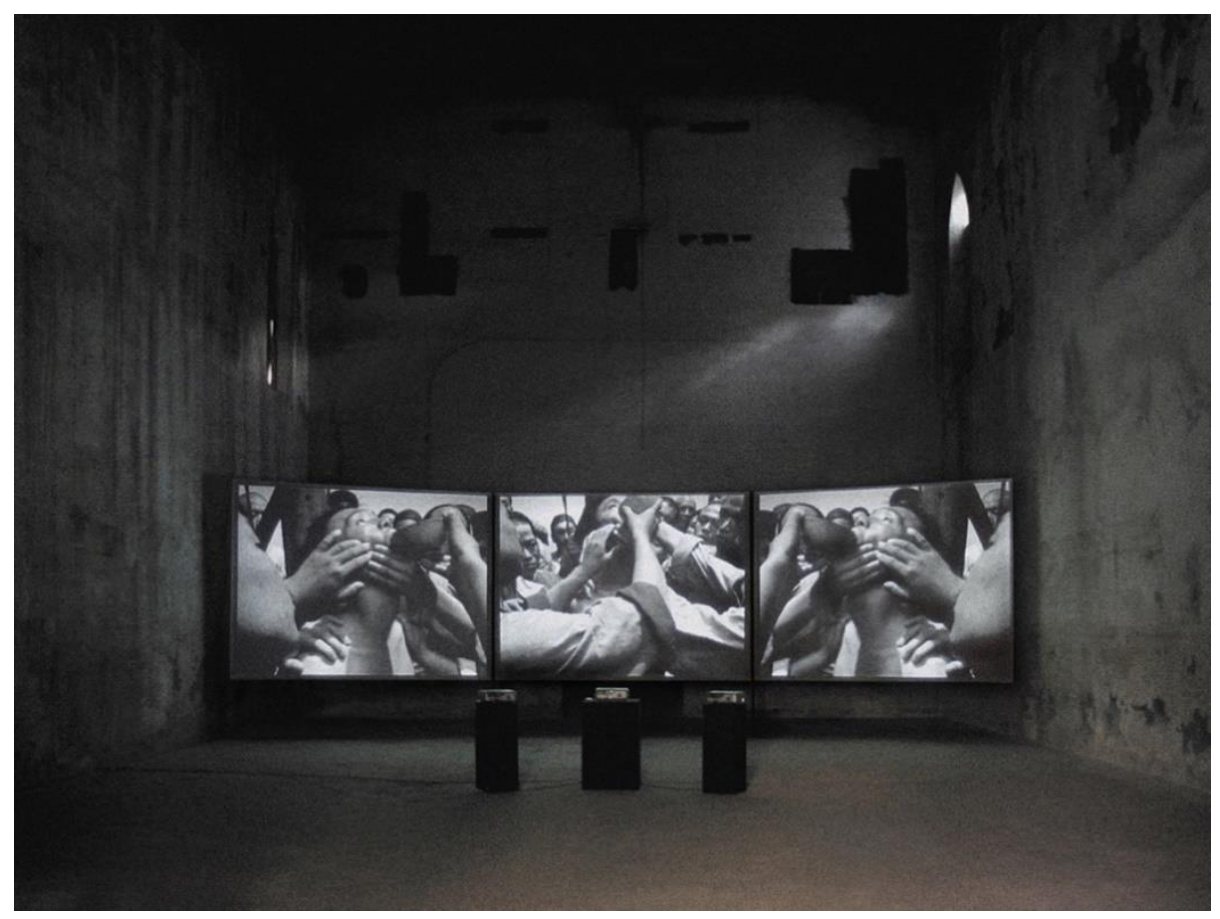

Figure 1. Picture of three-channel video installation (feeding opium): Chen Chieh-Jen, Lingchi: Echoes of a Historical Photograph (2002). Courtesy of the artist.

The second section begins after the executioners cut out two cavities on the victim's chest and the camera slowly intrudes into the two dark holes. In the cavities, five historical sites are presented in turn with each picture shown for around fifteen seconds: the Yuanmingyuan (the Old Summer Palace of Qing Dynasty); the laboratory of the Japanese Unit 
731 during World War II; the Green Island Prison during martial-law Taiwan; the plant of Radio Corporation of America (hereafter, RCA) in Taoyuan; and the Lien-Fu garment factory. Yuanmingyuan, the summer palace and the main residence for the Qianlong Emperor, was sacked and destroyed by Anglo-French expeditions in 1860 and the Eight-Nation Alliance in 1900. The Unit 731 laboratory was one of the most inhumane and notorious sites administered by Japanese troops during the Second Sino-Japanese War and World War II. This laboratory was where the Japanese carried out extreme tortures to human bodies, including vivisection and biological weapons testing. Those tortures were rationalised as necessary steps in advancing medical progress and modernizing Japanese imperialist weapons. The Green Island Prison was an exemplar of both body torture and mental torment under the dictatorship of Chiang's family. The RCA plant and Lien-Fu factory were crimes committed by capitalists. The RCA plant permanently polluted the nearby environment, directly causing hundreds of employees to die of related cancers ("Four Hundred Million Gone! The Polluted Multinational Corporation Doesn't Have to Pay for Its Crime"). The image of the Lien-Fu factory discloses a site of capitalist exploitation of labourers ("The Lien-Fu Garment Factory Shut Down Maliciously. Employees’ Rights Are Undue after Twelfth Years”).

After the sequence of the historical sites, the victim's body becomes a camera. Accompanied by a feeble sound of static electricity contacting skin, the perspective changes from looking inward to outward the cavities, from which one sees the scene of the lingchi execution again. The first cavity captures a Western photographer and curious Qing-dynasty onlookers. The Western photographer nudges away from an onlooker, operating his stereo camera to take the best shot of the victim. What follows is a contemporary scene: two women standing aside a tormented young man clad in a working shirt. These women are female labourers of the Lien-Fu factory. They roll up the young man's shirt, revealing the same kind of lingchi wounds on his chest. With a feeble sound again, the lens returns us back to the historical lingchi scene. The victim's joyful face reflects on the lens of the stereo camera. The juxtaposition between the historical and contemporary scenes here connects the imperialist violence and capitalist exploitation of human bodies.

The Lien-Fu women workers in the second bodily cavity become protagonists in Factory. Chen came to know the laid-off Lien-Fu workers in 2002; he reconvened them to enact their duties in the shut-down factory. Compared to the protagonist in Lingchi who is portrayed by an actor, the workers are acting as themselves in Factory. Regarding their role identity, Chen argues, "Although the female workers are playing themselves, in some sense, 
they are not real labourers. They are unemployed female workers, actors, and thinkers who are in 'anomalous' mental status. In other words, they are more like 'indefinable beings' in this video" (Lin and Cheng 146-149). The triple identity of the female workers - "the labourers, unemployed people, anomalies"-reveals how capitalists treat labourers of the Third World; from exploitation to abandonment and exclusion. The mentality and subjectivity of laid-off workers are seldom addressed in the mainstream societal institutions and records, though they are a huge group in Taiwan's society.

The women workers and the young man are the incarnations of many other laid-off or abused workers today who replace the tormented imagery of the lingchi victim. Their abused position reflects Taiwan's 1990s economic conundrum - the industries shifted overseas. The contemporary surrogates, therefore, play as the pivotal nexus to frame Chen's genealogy of victims - starting with victims under imperialist invasions and extending to the incalculable exploited labourers. While the first bodily cavity mirrors the Westerner's gaze, the second cavity reflects the victims suffering from the domination of capitalism in the postcolonial situation. The cut of the female workers in Lingchi hints at deep correlations between the weak colonised/Orientalised bodies and the exploited body in capitalist Taiwan's society resulting from the Cold War economic reliance and political structure. Lingchi is in some sense a miseen-abyme in which victims inside and outside the cavities are endlessly connected and generated along the course toward "progress" and "modernisation". The intersections of heterogeneous spaces and times that Chen constructs in Lingchi and Factory proffer dialectical space for contemplating how the colonised subject has been shaped or dissolved within the postcolonial and capitalist societies.

The third section of the Lingchi returns to the execution again. The executioners unbind the victim's hands, preparing to dismember his appendages. The shadows of the motion on the ground allude to the fact that the victim's hands were cut off. Turning his face to the sky, the victim sees a huge black funeral canopy. Later, after the video shows a sea upside down, a heavy rain abruptly comes down (Fig. 2). The rain not only dampens the victims and the executioners but also the Lien-Fu garment factory in the cavity. The video culminates in the original lingchi photo taken by the French soldier. 


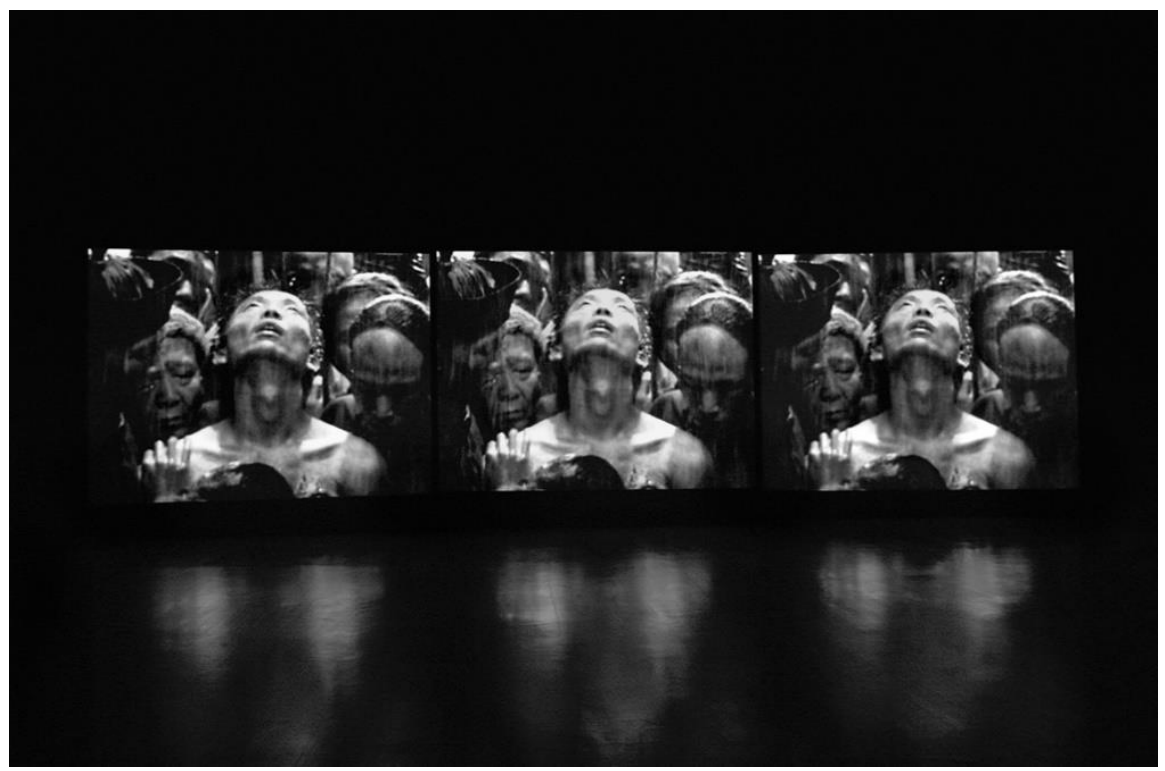

Figure 2. Picture of three-channel video installation (rain scene): Chen Chieh-Jen, Lingchi: Echoes of a Historical Photograph (2002). Courtesy of the artist.

When it comes to the effects of the victim's act, Lingchi generates several questions that need to be resolved. First of all, Lingchi is a video about the infamous capital penalty and one expects to see the act of flaying the film title announces, but throughout the film, Chen never shows us any act of torture. This absence, with the executioner's touch of the body and the facial performance, eroticises the whole execution. However, why does the victim appear intoxicated? Or, why does Chen represent this facial expression erotically? Although the victim was fed opium, there is no reason for his face to express ecstasy. While Chen himself describes this face as insinuating the trancelike states (Fig. 3), echoing the colonised subjects' powerlessness, few scholars suggest that it has to do with eroticism. I suggest it is because Bataille connects lingchi with eroticism and sadism in his book. Chen himself eroticises the subject in the video by rendering large amounts of close-ups of the face and shots of sexually suggestive bodily operations. By hyperbolising the trancelike state of the victim in the video, this video problematises the victim's subjugated position, prodding its audience to think about the dominant and hidden power relations embedded in postcolonial and neoliberal contexts. 


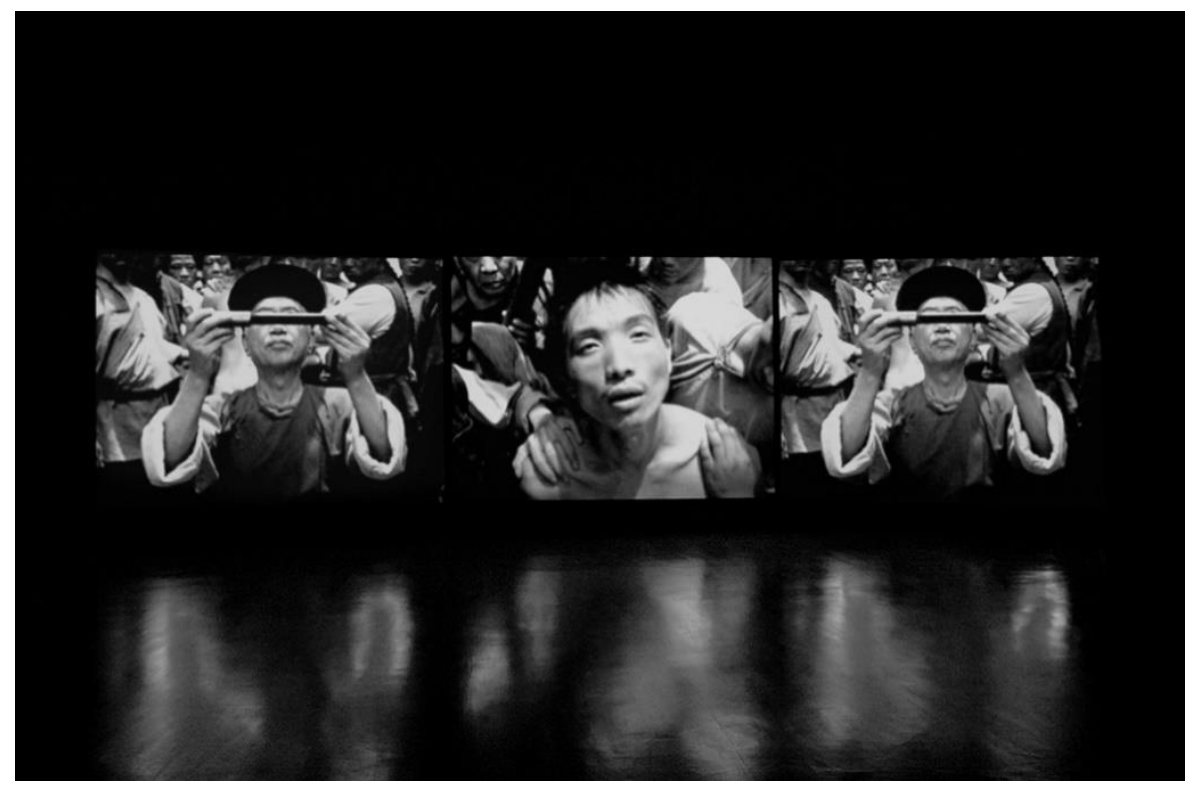

Figure 3. Picture of three-channel video installation (execution): Chen Chieh-Jen, Lingchi: Echoes of a Historical Photograph (2002). Courtesy of the artist.

\section{Metonymies: Bodies, Temporality, and Spatiality in Lingchi and Factory}

Sharing the identical concern with the labour issues, similar manoeuvres of spatiotemporal montage, figural synecdoche, and slow-motion camera movements, Lingchi and Factory can be viewed as companion works. In contrast to the long span of history that Lingchi draws on, Factory frames a relatively short moment in 1990s Taiwan, when the stock market slumped and industries relocated overseas. If Lingchi spells out the evolution of violence and sadism, Factory reveals a brutal scene of the present violence by depicting the silent working scenes of female workers as an indictment of the exploitation of callous capitalists. These women workers were employed by the Lien-Fu garment factory but were laid off without severance or retirement pay. The flourish of manufacturing in the 1960s were shown in the black-and-white clips cropped from official promotional films inserted in Factory. This prosperity contrasts with the dire situation of a large number of laid-off workers in the 1990s. Until 2003 when Chen filmed Factory, this group of female workers had already petitioned and protested for seven years. However, their wages were still undue by then. The return to and temporal occupation in the factory was to reflect the conundrum of workers whose voices had been intentionally neglected by the capitalists and government (Fig. 4). 


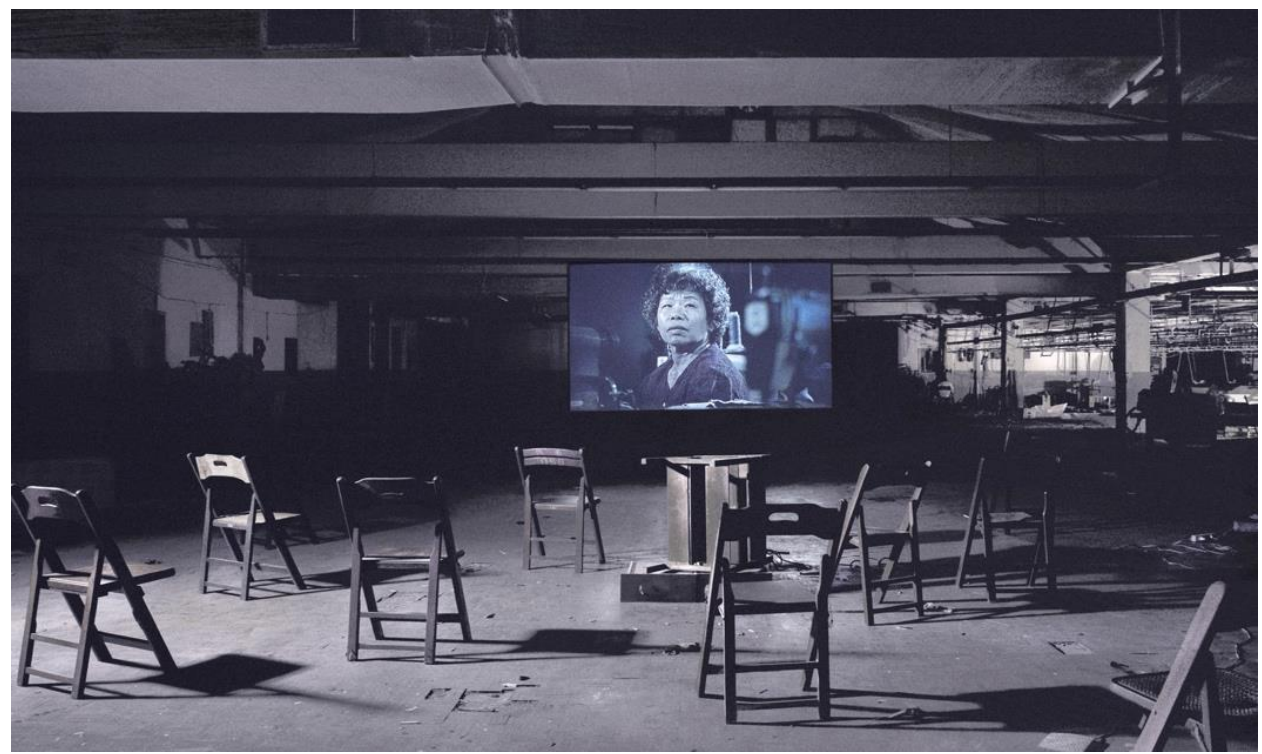

Figure 4. Picture of the on-site screening: Chen Chieh-Jen, Factory (2003). Courtesy of the artist.

To amplify the feeling of the drudgery of long labour protests, Chen shoots the female workers' gestures and the scenery of the factory in slow motion, framing the cinematic time at a grave and prolonged pace. In doing so, the working body of that specific space-time is suspended. The "that-has-been" aura evokes sympathy from its audience by rendering the suffering subjects in the great sense of loss but sublime dignity. In addition, the close-ups of those minute body movements - feet stepping on the pedals and busy hands working on clothes_-intensify sensorial perceptions generated by these subjects (Fig. 5).

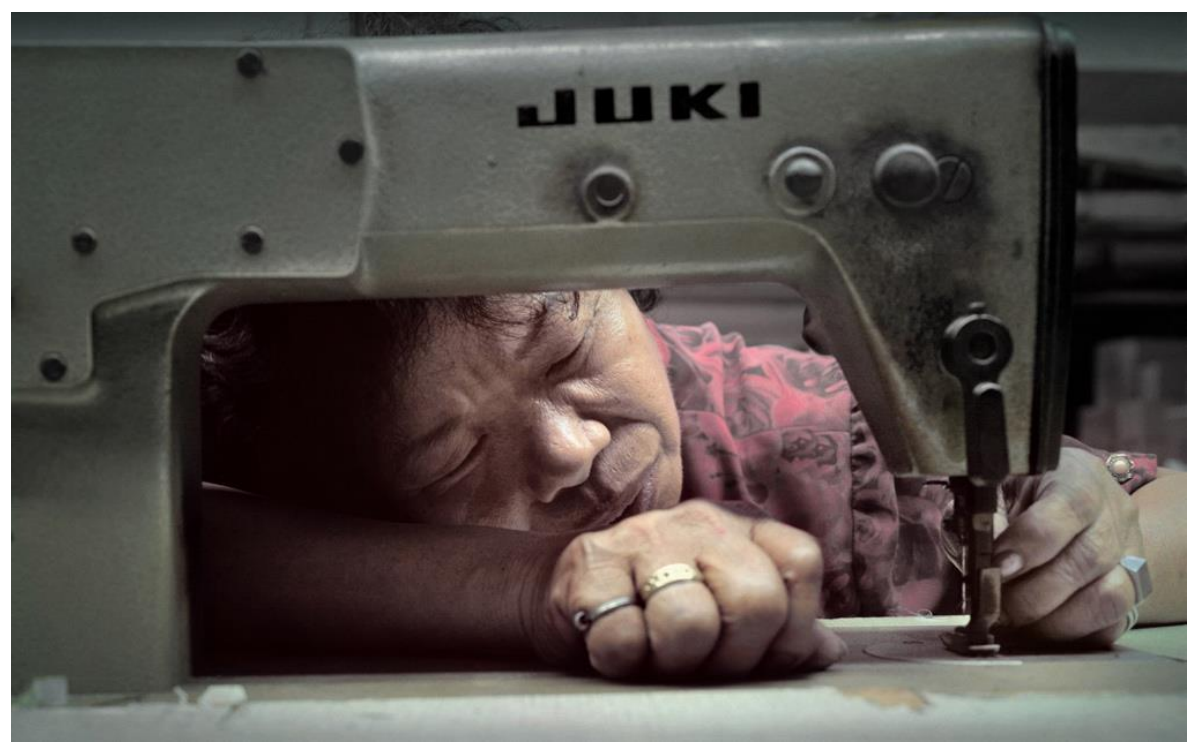

Figure 5. Close-up of the working scene: Chen Chieh-Jen, Factory (2003). Courtesy of the artist. 
Jacques Rancière points out that three different temporalities exist in Factory: the directed working time represented in the close-ups of factory workers threading needles; the capitalist time represented in the scene of two statue-like workers standing on a table and in the montage of found footage from promotional government documentary films; and the living time of the factory. He contends that the mixture of different fictionalised times creates "dissensus" that serves as the juncture for self-liberation (Rancière, "What Is Contemporary Artistic Time?"). What Rancière stresses here is the blurred boundaries between fictionalised time and real-time in that the past is conjured up and used to intervene in the present time. I propose that by connecting different temporalities in Factory, Chen makes invisible labour time visible, which not only reveals the exploited working modes in a capitalist society but also challenges the way we comprehend and interpret history in the present (Fig. 6).

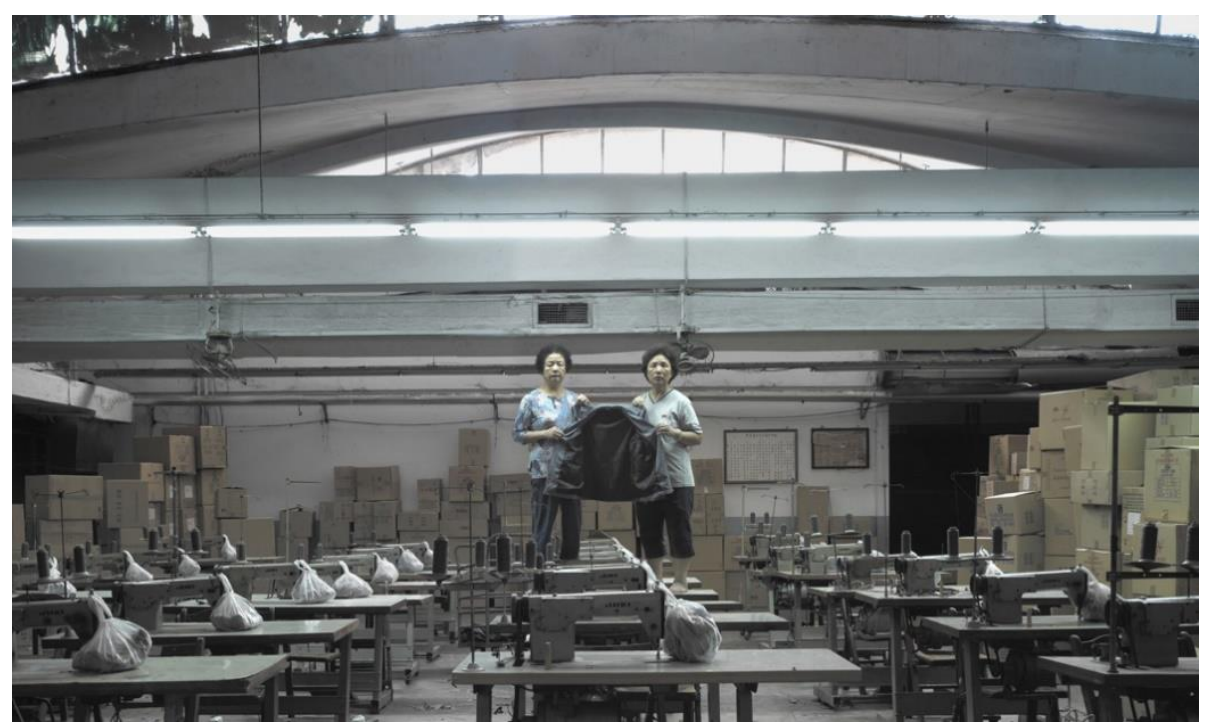

Figure 6. Still of Chen Chieh-Jen, Factory (2003). Courtesy of the artist.

The metonymies of the colonised and exploited bodies can be found in the surplus of materials and bodily wounds. The surplus of materials is represented by the piled artificial remnants in the abandoned factory. Images of sewing machines, wrapped bags of products on the working desks, piles of cartons, mountains of desks, the spinning fans, and the big jar of tea reflecting the distorted face of a worker loom large in this video. Factories are not only the birthplace of artificial goods but also, to some extent, the cemetery of old articles and dead 
machines. Making these piled articles into spectacles, Chen enlarges the absurdity of consumerism built on the endless vicious circle among excessive production, consumption, and waste. Compared to artificial productions, the situations of the labourers in manufacturing or poor countries are even more precarious. After life-long dedication in the factory, these female workers have already melded their bodies to their sewing machines, becoming the extensions of the working machine. These details are intensified in those close-ups of the worker's working feet and hands. The contrasts between bodies and instruments are reified not only in the scene in which the knife cuts the body in Lingchi but also in the close-up of the female worker using her fingers to thread the eye of the steel needle in Factory. Moreover, the eye of the steel needle resembles the bodily orifices of the lingchi victim cut out by steel knives. The workers are alienated and submerged in these hard, cold instruments, producing uniform clothes and jackets ironically used to warm and protect bodies. Working in the "body" of the structure, the female workers' bodies are immobile; their bodies were already incorporated in the assembly lines under the globalised capitalist system.

The bodily orifices manifest the violence and crimes committed by callous imperialists and capitalists. Bodily cavities and structures are the most conspicuous synecdoche in Lingchi. In Lingchi, after the executioner creates two wounds on the chest, they become the gateway of viewing both into and out of the body. The dark wounds, in other words, transform the body into a camera. From the cavities of the young victim, the audience sees the evidence of crime scenes. Among five sites in the cavity, the appearances of three structures resemble dark wounds: First, the two holes in the Japanese laboratory resemble the lens of a stereo camera. Second, the dark spaces framed by white pillars of the RCA factory are similar to the victim's cavities. Last, the layout and appearance of the Lien-Fu factory symbolise the standard modern concrete plant. The infinite cavities of bodies/structures/sites inside or outside of the images are referencing each other, meaning that cavities and injuries resulting from working in factories or incarceration in the jails are embedded in the memory of structures and imprinted on the next generation.

In addition, both Lingchi and Factory end with scenes of rain. The rain symbolises purification and oblivion. In the past, only the privileged class had the right to write, or rewrite, history. However unjust the tortures or treatments inflicted upon them, the colonised, minorities, and the humblest workers have never been given the rights and attention they deserve in their time or history. Unable to air their grievances within the institution, these immobile bodies are destined to be gradually washed away by time and excluded from 
orthodox history. To counter this authoritative violence, Chen invents new ways to position these powerless communities using two strategies: First, he creates new interpretations for individual events and arranges seemingly scattered and irrelevant incidents together to compete with the linear history. For example, he does not replicate lingchi as a savage torture rooted in feudal China or criticise its atrocity; rather, he accentuates the uncanny intervention of the Westerner's camera. Second, he synthesises the collective suffering experience across the Taiwan Strait to reinforce the ingrained and even communal memory of the colonial and postwar periods.

This uneven power structure between the authority and underprivileged is also revealed in Factory by montages. In the inserted black-and-white footage, one can see government officials jubilantly visiting the factory as well as a welcoming ceremony for the arrival of foreign officials. The prosperity in the governmental promotional footage demonstrates the conspiracy between totalitarianism and capitalism since the Cold War period. Even knowing the latent consequences - such as pollution, labour exploitation, lopsided trade relations - the government insisted on changing Taiwan into a labour-heavy island, with irrevocable repercussions. The juxtaposition of images of the present and the past constitutes an internal relationship among various incidents that happened in different times and spaces, rendering the video into a constellation of events, rather than a cohesive entity, that allows heterogeneous discourses to participate in examining the genealogy of the imposition on labourers.

\section{Conclusion}

In Lingchi and Factory, Chen reveals labour exploitation in post-Cold-War Taiwan by recycling the abused position of the lingchi victim. Chen frames labour exploitation as a new torture form under the division of the globalised capitalist system, highlighting that Taiwan's political and economic structure has been subjugated to Western powers since the Cold War. Therefore, "labour" is the nexus of these two videos. Apart from the ideas of politics and identity which have often been addressed in previous scholarship, this essay accentuates the importance of the aesthetic effects and performances in these videos. The metonymies of bodily cavities, the needle eye, and the dark sides of structures reinforce the figurations of the victim's wounds. Besides, the surplus materials and articles in the factory cannot compensate for the damage and exploitation of the body. I propose that the image of the female workers in the cavity links an abused position from imperialist invasion to capitalist exploitation and 
abandonment in contemporary Taiwan. The eroticisation of the lingchi victim's trancelike state and the threading act of the female worker problematises the Oriental gaze. This aesthetic eroticisation retrieves the agency of the photographed, counteracting the audience of the video with protracted and intolerable performances.

This article examines the relationship between Chen's early works. Revolt is Chen's first act by which he constructs the genealogy of the colonised subjects and expresses his personal experience during the martial law period in Taiwan. The video Lingchi reflects on how the colonised subject is represented and consumed under the Westerner's gaze and how it can redeem itself within the image. Lingchi also bridges the victims of imperialism and its contemporary surrogates-laid-off labourers. Factory indicts the uneven labour-capitalist system by reenacting the worker's jobs and presenting the residues of production. The suspended and undefinable position of these women workers reveals how labourers in the Third World became objects in late-capitalism society. The scenes of Lingchi and Factory are intersected with multiple times and spaces which are reconstructed together as heterogeneous and dialectical spaces, allowing different events to be inserted and discussed. One could, therefore, understand Chen's Lingchi and Factory as an extensive and deep reflection on the imperialist invasions, inhumane tortures under martial law, and labour exploitations under a capitalist society from Taiwan's post-colonial stance. 


\section{Works Cited}

“Four Hundred Million Gone! The Polluted Multinational Corporation Doesn't Have to Pay for Its Crime." Coolloud.org.tw, 14 June 2007, https://www.coolloud.org.tw/node/3699. Accessed 4 May 2021.

“The Lien-Fu Garment Factory Shut Down Maliciously. Employees' Rights Are Undue after Twelfth Years.” Coolloud.org.tw, 22 November 2008, https://www.coolloud.org.tw/node/30471. Accessed 4 May 2021.

Bataille, George. The Tears of Eros. Translated by Peter Connor, City Lights Publishers, 2001.

Berry, Michael. A History of Pain: Trauma in Modern Chinese Literature and Film. Columbia University Press, 2008.

Bourgon, Jérôme. “Agony by proxy. Voices, views, and values about lingchi execution.” 11 November, 2005, http://turandot.chineselegalculture.org/Essay.php?ID=40\&. Accessed 5 May 2021.

---. "Execution by lingchi of pseudo-Fu-zhu-li." http://turandot.chineselegalculture.org/Event.php?ID=10. Accessed 1 May 2021.

Brook, Timothy, Jérôme Bourgon, and Gregory Blue. Death by a Thousand Cuts. Harvard University, 2008.

Chen, Chieh-Jen. Picture of three-channel video installation (feeding opium): Lingchi: Echoes of a Historical Photograph. 2002. Courtesy of the artist.

Chen, Chieh-Jen. Picture of three-channel video installation (rain scene): Lingchi: Echoes of a Historical Photograph. 2002. Courtesy of the artist.

Chen, Chieh-Jen. Picture of three-channel video installation (execution): Lingchi: Echoes of a Historical Photograph. 2002. Courtesy of the artist.

Chen, Chieh-Jen. Picture of the on-site screening: Factory. 2003. Courtesy of the artist. Chen, Chieh-Jen. Close-up of the working scene: Factory. 2003. Courtesy of the artist. Chen, Chieh-Jen. Still of Factory. 2003. Courtesy of the artist. 
Chen, Chieh-Jen. Interview by Amy Huei-Hwa Cheng. "A History of the Photographed Subject: On Lingchi-Echoes of a Historical Photograph.” ITPARK, December 2002, http://www.itpark.com.tw/people/essays_data/43/166/en. Accessed 8 May 2021.

---. Interview by Yi-Hsiu Lin and Amy Huei-Hwa Cheng. "Bianwen and ReverberationsImages, Production, Action, and Documents of Chieh-jen Chen." ARTCO no. 279, 2015, pp. 146-149.

https://www.thestandnews.com/art/\%E8\%AE\%8A\%E6\%96\%87\%E8\%88\%87\%E6\% AE\%98\%E9\%9F\%BF\%E9\%99\%B3\%E7\%95\%8C\%E4\%BB\%81\%E7\%9A\%84\%E5 \%BD\%B1\%E5\%83\%8F-\%E7\%94\%9F\%E7\%94\%A2\%E8\%A1\%8C\%E5\%8B\%95\%E8\%88\%87\%E6\%96\%87\%E4\%BB\%B6/. Accessed 2 May 2021.

Liu, Joyce C.H. “The Gaze of Revolt: Chen Chieh-Jen's Historical Images and His Aesthetics of Horror." Cultural Dilemmas during Transitions Conference, Polish Academy of Sciences, Warsaw, 15-17, October 2000,

http://www.srcs.nctu.edu.tw/joyceliu/mworks/mw-interart/TaiwanArt/english.htm, Accessed 7 May 2021.

Rancière, Jacques. Transcribed by Yuan-Yuan Cheng. "What Is Contemporary Artistic Time?” Talk, 12 May 2013, UCAA Center for Contemporary Art, Beijing. http://collection.sina.com.cn/ddys/20130717/1018120498.shtml. Accessed 2 May 2021.

Sontag, Susan. Regarding the Pain of Others. Farrar, Straus and Giroux, 2003.

Wei, Chu-Chiun. "The Aesthetics of the Multitude in Chen Chieh-Jen's Lingchi: Echoes of a Historical Photograph (2002)—A Genealogy." Journal of Contemporary Chinese Art, vol. 5, no. 1, 2018, pp. 61-76. 


\section{Author Biography}

Hsin-Yun Cheng is a PhD student in Visual and Cultural Studies at the University of Rochester. She is interested in performance studies, video art, and the relationship between contemporary art production, post-colonial situation, and neoliberalism. Her writings have appeared in peerreviewed journals including Journal of Taipei Fine Arts Museum, Art Forum (National Taiwan Normal University), and so on. 